\title{
The lon gene, encoding an ATP-dependent protease, is a novel member of the HAIR/HspR stress-response regulon in actinomycetes
}

\author{
André Sobczyk, ${ }^{1,2}$ Audrey Bellier, ${ }^{1}$ Julie Viala $^{1}$ and Philippe Mazodier ${ }^{1}$
}

Author for correspondence: Philippe Mazodier. Tel: +3314568 88 42. Fax: +3314568 8938 . e-mail:mazodier@pasteur.fr

1 Unité de Biochimie Microbienne, Institut Pasteur, 25 rue du Docteur Roux, 75724 Paris Cedex 15 , France

2 VIVALIS SA, CHU de Nantes Hôtel-Dieu, Place A. Ricordeau, 44093 Nantes Cedex 1, France

\begin{abstract}
Members of a family of ATP-dependent proteases related to Lon from Escherichia coli are present in most prokaryotes and eukaryotes. These proteases are generally reported to be heat induced, and various regulatory systems have been described. The authors cloned and disrupted the lon gene and studied the regulation of its expression in Streptomyces lividans. Ion is negatively regulated by the HspR/HAIR repressor/operator system, suggesting that Lon is produced concomitantly with the other members of this regulon, DnaK and ClpB. The lon mutant grew more slowly than the wild-type and spore germination was impaired at high temperature. Nevertheless its cell cycle was not greatly affected and it sporulated normally.
\end{abstract}

Keywords: heat shock regulation, Streptomyces, HspR, protease, DnaK

\section{INTRODUCTION}

Most bacterial proteins are stable, with a half-life that is longer than the generation time of the cell. However, some proteins with important physiological roles are unstable and are degraded in a few minutes (Gottesman \& Maurizi, 1992). In Escherichia coli, these proteins are generally degraded by ATP-dependent intracellular proteases, two families of which have been well characterized: the Lon and Clp serine proteases. The Clp protease is composed of a catalytic subunit $(\mathrm{ClpP})$ and regulatory subunits (ClpA/ClpX). Lon (also called La) is an $87 \mathrm{kDa}$ homo-tetramer. The role of Lon in E. coli is well known, as several of its substrates have been identified. Lon is involved in cell division, in the regulation of colanic acid production and in the growth of phage lambda. In E. coli, Lon is responsible for the degradation of most abnormal proteins, in particular those produced under stress conditions (Goldberg et al., 1994; Tomoyasu et al., 2001).

The ATP-dependent proteases are central enzymes in the regulation of differentiation in several bacteria. Indeed, in E. coli FtsH degrades the specific heat-shock sigma factor, $\sigma^{32}$ (Herman et al., 1995), and ClpXP degrades the specific stationary-phase sigma factor, $\sigma^{\mathrm{s}}$ (Schweder et al., 1996). In Bacillus subtilis, ClpP degrades ComK, the central regulator of competence (Turgay et al., 1998), and at low pHs Lon degrades the

Abbreviation: HSP, heat-shock protein. sporulation sigma factor, $\sigma^{\mathrm{H}}$ (Liu et al., 1999). The Lon protease also plays an essential role in the formation of asymmetrical flagella in Caulobacter crescentus (Wright et al., 1996).

Streptomycetes are model bacteria for the study of differentiation mechanisms. In vitro these soil bacteria follow a differentiation cycle that lasts about a week. The germinated spores form basal or vegetative mycelia. A few days later, aerial mycelia are formed from these structures. These new mycelia partition themselves to form chains of spores that are dispersed following maturation (Hopwood, 1999). The interest of Streptomyces as a model for studying differentiation is reinforced by the fact that this morphological phenomenon is generally accompanied by the production of secondary metabolites. Currently, $70 \%$ of industrially produced antibiotics come from these bacteria.

Regulatory processes associated with spore formation from aerial hyphae and germination take place in cells that do not divide and thus the pre-existing regulatory proteins cannot be diluted. Two types of mechanism can be used to palliate the absence of dilution: the activation/inactivation of central regulators by modification (for example by phosphorylation or methylation), or specific degradation. These considerations led us to study the role of ATP-dependent proteases in the control of the cell cycle (De Crecy-Lagard et al., 1999; Viala et al., 2000).

The ATP-dependent proteases Clp, Lon and FtsH are heat-shock proteins (HSPs) in most bacterial species and 
their regulation is well documented in E. coli and B. subtilis. Although the induction of HSPs is a universal response, a number of mechanisms control HSP synthesis in different organisms. The transcription of heatshock genes is regulated by both positive and negative mechanisms. In bacteria, the regulation of the heatshock response was first studied in E. coli and shown to rely on the level and activity of specific sigma factors, $\sigma^{32}$ and $\sigma^{24}$ (for reviews see Bukau, 1993; Yura et al., 1993). These sigma factors are required for the recognition of specific heat-shock promoters associated with heatshock genes by the RNA polymerase. The regulation of expression was shown to depend largely on the stability of the sigma factor. Thus, an increase in temperature leads to a rapid increase in the level of active $\sigma^{32}$ due to an increase in the synthesis of this molecule and its stabilization. At $30^{\circ} \mathrm{C}$, the DnaK chaperone system destabilizes $\sigma^{32}$ and sequesters it in an inactive state that can be degraded by the FtsH protease (Herman et al., 1995). Heat shock causes the denaturation of cellular polypeptides: the DnaK system binds these misfolded polypeptides and releases $\sigma^{32}$, in a mechanism allowing positive feedback regulation.

This general dependence on sigma factors for heatshock regulation is not conserved in prokaryotes. Indeed, in most organisms, important hsp genes are controlled exclusively by specific repressors. This is well documented in Bacillus and Streptomyces. In Streptomyces, the synthesis of major HSPs, such as the widespread molecular chaperones DnaK, ClpB, GroEL and HSP18, is negatively controlled at the transcriptional level by at least three different repressors. The control of groE gene expression involves an invertedrepeat element (called CIRCE) that is highly conserved among eubacteria, and the HrcA repressor (Grandvalet et al., 1998). The dnaK operon and $c l p B$ belong to the HspR/HAIR regulon (Bucca et al., 1997; Grandvalet et al., 1999). The HspR repressor-HAIR operator system is used in some bacteria (Spohn \& Scarlato, 1999) but is not widespread. In particular, it is not used in low- $\mathrm{G}+\mathrm{C}$ Gram-positive bacteria.

In this study, the genome sequence of S. coelicolor (www. sanger.ac.uk/Projects/S_coelicolor/) was searched for the HAIR motif CTTGAGT- $\mathrm{N}_{7}$-ACTCAAG. A HAIR sequence was found upstream of a gene closely related to the lon gene. We demonstrated that lon belongs to the HspR/HAIR regulon.

\section{METHODS}

Bacterial strains, media, plasmids. S. lividans TK24 was obtained from the John Innes Culture Collection, Norwich, UK. YEME medium was used for liquid cultures, and R2, R2YE (Hopwood et al., 1985) or NE (Murakami et al., 1989) were used to grow $S$. lividans on plates.

pIJ8600 was used for controlled gene expression in S. lividans using the thiostrepton-inducible promoter pTipA (Sun et al., 1999). pGM160ه (Muth et al., 1989) was used to construct the disruption derivatives. Thiostrepton, viomycin and hygromycin were added to plates at final concentrations of
$30 \mu \mathrm{g} \mathrm{ml}^{-1}, 25 \mu \mathrm{g} \mathrm{ml}^{-1}$ and $250 \mu \mathrm{g} \mathrm{ml}^{-1}$, respectively, as appropriate. Cassettes containing resistance genes (BlondeletRouault et al., 1997) were used for gene disruption experiments. E. coli TG1 (Gibson, 1984) was used as the general cloning host and E. coli strains were grown in Luria-Bertani (LB) broth supplemented with $200 \mu \mathrm{g}$ hygromycin $\mathrm{ml}^{-1}, 10 \mu \mathrm{g}$ viomycin $\mathrm{ml}^{-1}$ or $100 \mu \mathrm{g}$ ampicillin $\mathrm{ml}^{-1}$ when needed. pUC19, pUC18 (Yanisch-Perron et al., 1985) and pBluescript-SK were used as cloning vectors in E. coli.

DNA manipulation and plasmid construction. Standard cloning procedures were used to produce all plasmids (Sambrook et al., 1989). Restriction and modification enzymes were used according to the manufacturers' recommendations.

Cloning of the Ion gene of S. lividans. A pair of oligonucleotides, JU74 (5'-GAAGAATTCTACGGCGGTGCTGTCCCGAGA-3') and JU76 (5'-AAGAAGCTTCCAACGGCTGACGGCTCCTCC-3'), were designed based on the sequence of the S. coelicolor lon gene (Sanger Centre, Cambridge, UK; http://www.sanger.ac.uk/Projects/S_coelicolor/). These oligonucleotides were used to amplify the lon locus from $S$. lividans chromosomal DNA. We cloned a $3 \mathrm{~kb}$ PCR-amplified fragment containing the $S$. lividans lon locus and its promoter region. The PCR fragment was digested with EcoRI and HindIII and cloned into EcoRI/HindIII-digested pUC19 to generate pJV300. The $3 \mathrm{~kb}$ insert was sequenced and was found to contain one consensus HAIR motif centred $30 \mathrm{bp}$ upstream of the putative lon start codon.

Expression of Ion in E. coli. A $2.4 \mathrm{~kb}$ fragment containing the lon coding sequence from $S$. lividans was amplified by PCR using oligonucleotides AS58 (5'-ATACCATGGCTGCTGAGTCCGCCGCCTTC-3') and AS59 (5'-ATACTCGAGCGCTGCGACCGGAACCTCACG-3'). The PCR fragment was digested with $\mathrm{NcoI} / \mathrm{XhoI}$ and cloned into NcoI/XhoI-digested pET28a vector to yield pAS45. This plasmid allowed the overexpression of Lon under the control of the T7 promoter. A translational fusion added six carboxy-terminal histidine residues to Lon, which allowed affinity purification of the protein on a nickel column. Purified Lon was used to obtain antibodies in rabbit (carried out by Eurogentec).

Overproduction of HspR in $\boldsymbol{E}$. coli. The DNA fragment containing $S$. lividans $h s p R$ was amplified by PCR using oligonucleotides AS7 (5'-ATACATATGGACGGTCGGCGACGCAACCCG-3') and AS11 (5'-ATAAGATCTTCAGTCCGAGGACTGGCCGCG-3'). These primers introduced NdeI and BglII sites into the resulting $450 \mathrm{bp}$ DNA fragment. The NdeI site replaced the original $h s p R$ GTG translation start site with an ATG. The NdeI-BglII DNA fragment was cloned into the NdeI and BamHI sites of pET28a (Novagen) to yield pAS16, in which the T7 promoter was used to control gene expression. A translational fusion added 20 residues, including six histidines, to the amino terminus of HspR.

Purification of Lon protein to homogeneity and production of antibodies. E. coli BL21 ( $\lambda \mathrm{DE} 3)$ (pAS45) cells were grown at room temperature in LB medium containing kanamycin and chloramphenicol. When cultures reached an $\mathrm{OD}_{600}$ of $0 \cdot 6$, the production of Lon-His ${ }_{6}$ was induced by the addition of $0.1 \mathrm{mM}$ IPTG. After $3 \mathrm{~h}$ cells were harvested and washed twice in buffer A (20 mM phosphate buffer pH 7•4, $500 \mathrm{mM}$ $\mathrm{NaCl}, 20 \mathrm{mM}$ imidazole, $1 \mathrm{mM}$ DTT and $10 \%$, v/v, glycerol). The cell pellet was resuspended in $20 \mathrm{ml}$ buffer A supplemented with one tablet of Complete protease inhibitor cocktail (Boehringer Mannheim). Cells were disrupted in a French press (9000 p.s.i., $62 \mathrm{MPa}$ ). The soluble fraction was obtained by centrifugation at $4{ }^{\circ} \mathrm{C}$ and $30000 \mathrm{~g}$ and was loaded onto a 
$1 \mathrm{ml} \mathrm{Ni-NTA}$ column (Qiagen) that had been equilibrated with buffer A. Lon-His ${ }_{6}$ was eluted with a linear 20-300 mM imidazole gradient. The fractions with the highest protein concentration were pooled, dialysed for $2 \mathrm{~h}$ against buffer A and centrifuged at $13000 \mathrm{~g}$ for $5 \mathrm{~min}$. The supernatant $(5 \mathrm{ml})$ was loaded onto the Ni-NTA column for a second identical run. The second protein pool was dialysed against storage buffer $\mathrm{C}(20 \mathrm{mM}$ phosphate buffer $\mathrm{pH} 7 \cdot 4,50 \mathrm{mM} \mathrm{NaCl}$ and $10 \%$ glycerol) and aliquots were stored at $-80{ }^{\circ} \mathrm{C}$. Lon- $\mathrm{His}_{6}$ concentration was determined by the Bradford method. This purified protein was used to raise polyclonal antibodies against Lon.

Ion-disrupting plasmid. The BamHI cassette containing the hygromycin-resistance gene purified from $\mathrm{pHP} 45 \Omega \mathrm{HygR}$ (Blondelet-Rouault et al., 1997) was used to disrupt the $S$. lividans lon gene. The Bam $\mathrm{HI} \Omega \mathrm{HygR}$ cassette was ligated into the lon Bam HI site in pAS45, 878 bp downstream from the lon ATG codon. Two plasmids were generated: pAS47 and pAS48. The bygR gene was transcribed in opposite direction to lon in pAS48. pAS48 was further digested with $\mathrm{XbaI} / \mathrm{NcoI}$. The sites for these enzymes are located close together in pAS48. Thus, we cloned the whole pAS48 plasmid between the $\mathrm{NcoI}$ and $\mathrm{XbaI}$ sites of pGM1604. The resulting S. lividans replication-thermosensitive plasmid was called pAS49 and was used to disrupt lon.

$\boldsymbol{h} s p \boldsymbol{R}$-disrupting plasmid. Inverse-PCR (I-PCR) was used to clone $h s p R$ and large DNA fragments of its surrounding sequences from $S$. lividans. This allowed the region $3^{\prime}$ of $h s p R$ to be cloned in the absence of sequence data and also created an EcoRI site $100 \mathrm{bp}$ downstream of the $h s p R$ translation start site (ATG) into which a resistance gene could be inserted. We

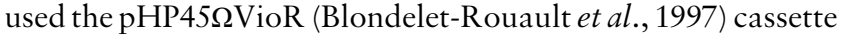
containing the viomycin phosphotransferase gene $(v p h)$ from Streptomyces vinaceus for disruption experiments. S. lividans chromosomal DNA (5 $\mu \mathrm{g}$ ) was digested with Pst I and ligated after dilution to facilitate the intramolecular ligation of the DNA fragments. Two divergent oligonucleotides were designed, AS1 (5'-ATAGAATTCTGGCGCAGCGTCTGCGGGTG-3') and AS2 (5'-ATAGAATTCCGCGACATCGAACTGCTCCG-3'), based on published S. coelicolor (cosmid H35, Sanger Centre sequencing project) and S. albus (Grandvalet et al., 1997) hspR sequences. PCR was performed on $500 \mathrm{ng}$ ligated $S$. lividans TK24 chromosomal DNA, 20 pmol AS1 and AS2, 10\% DMSO, $200 \mathrm{mM}$ of each dNTP and $1 \mathrm{U}$ $P f u$ DNA polymerase (Promega) as recommended by the manufacturer. PCR generated a $5.5 \mathrm{~kb}$ I-PCR fragment with enough DNA sequence upstream and downstream of $h s p R$ to favour double recombination in $S$. lividans. After purification, the PCR fragment was digested with EcoRI and cloned into pBluescript-SK to generate pAS2. The two $h s p R$ DNA fragments obtained after an EcoRI/PstI digestion of pAS2 were purified separately, ligated to the EcoRI viomycin cassette and cloned into the PstI site of pBluescript-SK $(-)$ to give pAS3. pAS3 was selected for its ability to confer both ampicillin and viomycin resistance to E. coli. Inserts from pAS2 and pAS3 were partly sequenced to confirm the constructs. In pAS3, the $v p h$ gene is transcribed in the opposite direction to $h s p R$. pAS3 was further digested with $\mathrm{XbaI} / \mathrm{NcoI}$ to give a $7.6 \mathrm{~kb}$ DNA fragment encompassing the following $S$. lividans sequences: the $3^{\prime}$ end of grpE, the dnaJ gene, disrupted $h s p R$ and a $3 \mathrm{~kb}$ region downstream of $h s p R$. This DNA fragment was cloned into the $\mathrm{XbaI} / \mathrm{NcoI}$ sites of pGM160s to yield the $S$. lividans replication-thermosensitive hspR-disrupting plasmid, pAS25.

Transformation procedures and screening of mutants. The lon gene from $S$. lividans was disrupted after transformation of protoplasts with pAS49. The TK24 protoplasts were prepared and transformed as described by Hopwood et al. (1985). After $24 \mathrm{~h}$ incubation thiostrepton was added to the plates. $\mathrm{Tsr}^{\mathrm{R}}$ colonies were tested for the presence of hygromycin resistance. Two doubly resistant clones were incubated in $10 \mathrm{ml}$ YEME medium supplemented with hygromycin and grown for 3 days at $30{ }^{\circ} \mathrm{C}$ before the crossover selection. To obtain a mutant due to homologous recombination at the lon locus, $10 \mathrm{ml}$ YEME without antibiotics was inoculated with a drop of the pre-culture. The culture was incubated for 3 days with vigorous shaking at $40^{\circ} \mathrm{C}$ to prevent pAS49 from replicating. Different dilutions $\left(1 / 10^{4}, 1 / 10^{5}\right.$ and $\left.1 / 10^{6}\right)$ of cells were plated onto R5 medium supplemented with hygromycin. $\operatorname{Hyg}^{\mathrm{R}}$ clones were finally patched on both R5+hygromycin and R5 + thiostrepton plates to select $\mathrm{Hyg}^{\mathrm{R}}$ and $\mathrm{Tsr}^{\mathrm{S}}$ clones. Insertion of the hygromycin cassette in the lon gene was controlled by a series of PCR amplifications using oligonucleotides specific to lon and to the cassette.

A S. lividans lon $h s p R$ double mutant was obtained by transforming protoplasts of the $S$. lividans lon mutant with the $h s p R$-disrupting plasmid, pAS25. The mutants were selected as above but with viomycin instead of hygromycin.

RNA analysis. RNA was prepared as described previously (Servant \& Mazodier, 1996). The transcription start site upstream of lon was located by primer extension using oligonucleotide AB10 (5'-GTCGATGCGCGGGACGAGGAG-3') as previously described (Grandvalet et al., 1999).

Gel retardation assay. A 300 bp DNA fragment encompassing $200 \mathrm{bp}$ of lon promoter region and $100 \mathrm{bp}$ of the $5^{\prime}$ end of the lon coding sequence was PCR-amplified with oligonucleotides JU74 and JU75 (5'-GCGGGGCTTGCCGGGCTCGGA-3'). The purified fragment was end-labelled with $\left[\gamma^{32}{ }^{32} \mathrm{P}\right] \mathrm{ATP}$ by the T4 polynucleotide kinase method. Crude extracts with or without overexpressed HspR in E. coli (IPTG induction) were incubated with the labelled probe for $15 \mathrm{~min}$ at $25^{\circ} \mathrm{C}$. These were incubated in $10 \mu \mathrm{l}$ gel-shift buffer $(10 \mathrm{mM}$ Tris $/ \mathrm{HCl}$ $\mathrm{pH} 7 \cdot 5,10 \mathrm{mM} \mathrm{MgCl}, 1 \mathrm{mM}$ DTT, $0 \cdot 1 \%$ Triton X-100, $50 \mathrm{mM} \mathrm{NaCl}$ and $10 \%$ glycerol) and $1 \mu \mathrm{g}$ sonicated herring sperm DNA. Samples were subjected to electrophoresis in $6 \%$ polyacrylamide gels containing $50 \mathrm{mM}$ Tris $/ \mathrm{HCl} \mathrm{pH} 8$, $400 \mathrm{mM}$ glycine, $1.7 \mathrm{mM}$ EDTA and $2.5 \%$ glycerol. Samples were separated for $1 \mathrm{~h}$ at $100 \mathrm{~V}$. Finally, the gels were dried and exposed to film.

Western immunoblot analysis. Total protein extracts were prepared from $S$. lividans wild-type strain TK24 or S. lividans mutants after being grown in YEME, supplemented with the appropriate antibiotic if needed. Cells were incubated for $24 \mathrm{~h}$ at $30{ }^{\circ} \mathrm{C}$, and then samples were subjected to a $40 \mathrm{~min}$ heat shock at $40{ }^{\circ} \mathrm{C}$. Proteins were separated on polyacrylamide denaturing gels (10\% SDS-PAGE) before being electrotransferred to Immobilon membranes (Amersham). Antigens were detected by ECL Western blotting in the presence of rabbit polyclonal antibodies raised against purified S. lividans Lon$\mathrm{His}_{6}$.

\section{RESULTS}

The genome sequence of $S$. coelicolor from the Sanger Centre was searched for the HAIR motif by use of the appended 'DNA motif search' program. In addition to the HAIR motifs associated with $d n a K$ and $\operatorname{clpB}$, a HAIR sequence was found upstream of a gene closely related to the lon gene, encoding the ubiquitous ATPdependent protease. The nucleotide sequence upstream 
from lon contains the following sequence: ATTGAGT$\mathrm{N}_{7}$-ACTCAAC, which is similar to the HAIR consensus motif CTTGAGT- $\mathrm{N}_{7}$-ACTCAAG of the HspR-binding site (Grandvalet et al., 1999). This led us to clone the lon gene with oligonucleotides derived from the S. coelicolor sequence.

\section{Cloning of the lon gene of S. lividans}

A pair of oligonucleotides (JU74 and JU76) were designed based on the sequence of the S. coelicolor lon gene and used to amplify the lon locus from S. lividans chromosomal DNA. The gene was cloned in pUC19, yielding pJV300. Partial DNA sequence determination confirmed the clone and showed more than $99 \%$ identity with lon of S. coelicolor.

\section{Ion mutant}

The chromosomal lon gene was disrupted by a double recombination event using the pAS49 vector containing lon: $h y g R$. Candidate $\mathrm{Hyg}^{\mathrm{R}} \mathrm{Tsr}^{\mathrm{S}}$ clones were analysed. The correct integration of hygR in chromosomal lon was checked by PCR using pairs of oligonucleotides annealing to the byg cassette and to the lon chromosomal locus outside the region cloned in pAS49.

The wild-type strain grew faster than the lon mutant on all the liquid and solid media tested at $30^{\circ} \mathrm{C}$ (NE, R5 YEME). However, the lon mutant formed aerial mycelium on plates $30 \mathrm{~h}$ after the wild-type and ultimately sporulated. Spores of the lon mutant failed to form colonies on NE plates after 1 week at $40^{\circ} \mathrm{C}$, whereas the wild-type produced colonies within $2-3$ days, suggesting that the germination process is thermosensitive in the mutant (data not shown).

\section{Regulation of expression: Ion hspR double mutant}

To confirm the role of HspR in the regulation of lon, a lon:: hygR hspR::vioR double mutant was constructed. The chromosomal $h s p R$ was disrupted by a double recombination event using the pAS25 vector containing $h s p R: v i o R$ and the procedure described above used to disrupt lon except that candidate $\mathrm{Vio}^{\mathrm{R}} \mathrm{Tsr}^{\mathrm{S}}$ clones were analysed.

Bucca et al. (1997) attempted insertion by a double crossover event of the hygromycin-resistance gene into the $5^{\prime}$ end of $h s p R$ in S. lividans, but without success. Only the entire mutating plasmid could be integrated, leading to a construction containing the mutated $h s p R$ gene and an intact copy of $h s p R$. Our attempts to use pAS25 to integrate a viomycin cassette into the middle of $h s p R$ in S. lividans by a double crossover event failed repeatedly in the wild-type strain; however, as, shown here, the $h s p R:: v i o R$ mutant was obtained readily in the lon mutant. These results indicate that a high level of lon expression in Streptomyces may be toxic for the cell (i.e. long-term full induction due to a complete knockout mutation of $h s p R)$. Toxicity related to lon overexpression will be investigated in future work.

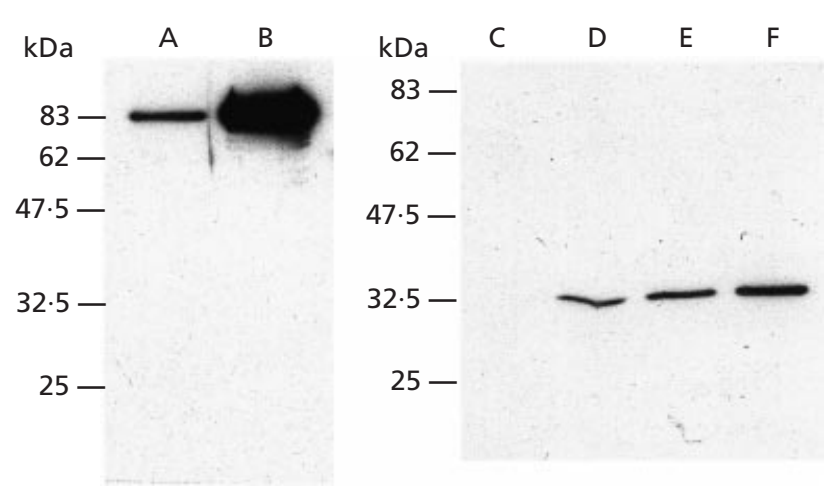

Fig. 1. Western blot analysis of lon expression. Total cell extracts were prepared from the wild-type strain (lanes $A$ and $\mathrm{B})$, the lon mutant (lanes $\mathrm{C}$ and $\mathrm{D}$ ), or the $h s p R$ lon double mutant (lanes $\mathrm{E}$ and $\mathrm{F}$ ). Cultures were grown at $30^{\circ} \mathrm{C}$ (lanes $\mathrm{A}$, $\mathrm{C}$ and $\mathrm{E}$ ) or were subjected to a $40 \mathrm{~min}$ heat shock at $40^{\circ} \mathrm{C}$ (lanes B, D and F). Different amounts of total protein were loaded: $5 \mu \mathrm{g}$ in lanes $\mathrm{A}$ and $\mathrm{B}, 10 \mu \mathrm{g}$ in lanes $\mathrm{C}-\mathrm{F}$. Blots were probed with polyclonal antibodies directed against the $S$. lividans Lon protein. These antibodies detect the bands corresponding to the $90 \mathrm{kDa}$ Lon protein, and a $30 \mathrm{kDa}$ peptide which corresponds to the predicted $(29.5 \mathrm{kDa})$ truncated Lon protein.

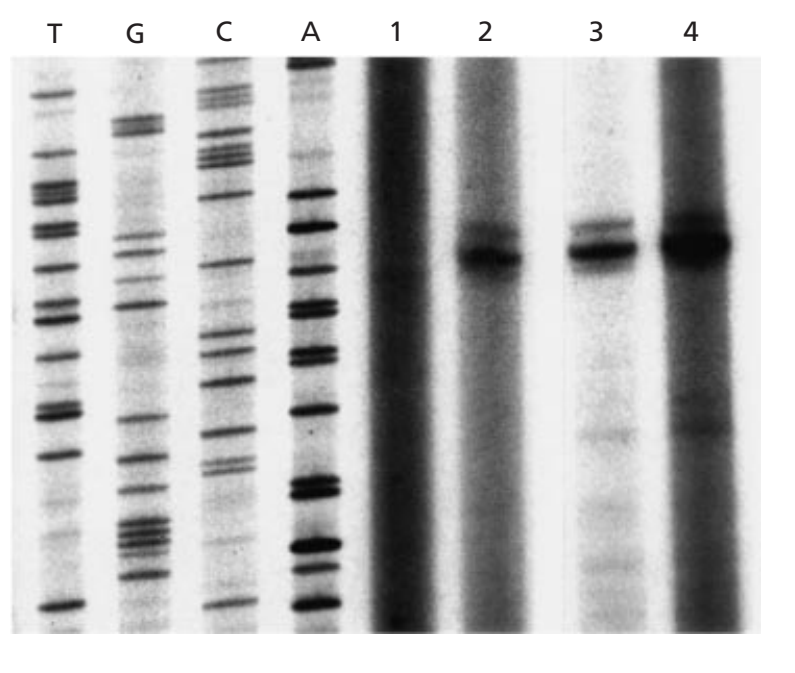

Fig. 2. Mapping of the S. lividans lon transcription start site by primer extension. Dideoxy-terminated DNA sequencing reaction products (lanes $A, C, G$ and $T$ ) and primer extension reaction products are shown. RNA was isolated from the wild-type strain (lanes 1 and 2) or the $h s p R$ lon mutant (lanes 3 and 4). Cells were grown at $30^{\circ} \mathrm{C}$ (lanes 1 and 3 ) or subjected to heat shock for $40 \mathrm{~min}$ at $40^{\circ} \mathrm{C}$ (lanes 2 and 4 ).

\section{Western blot of Lon}

Proteins extracted from the wild-type strain, the lon mutant and the lon $h s p R$ double mutant grown at $30^{\circ} \mathrm{C}$ or subjected to heat shock were analysed by Western blotting using anti-Lon antibodies. In the wild-type a $90 \mathrm{kDa}$ heat-inducible protein was detected (Fig. 1, lanes $\mathrm{A}$ and $\mathrm{B})$. In the lon mutant the $90 \mathrm{kDa}$ Lon protein was not detected (lanes C and D), but a $30 \mathrm{kDa}$ peptide, 
1 2 3 4 6

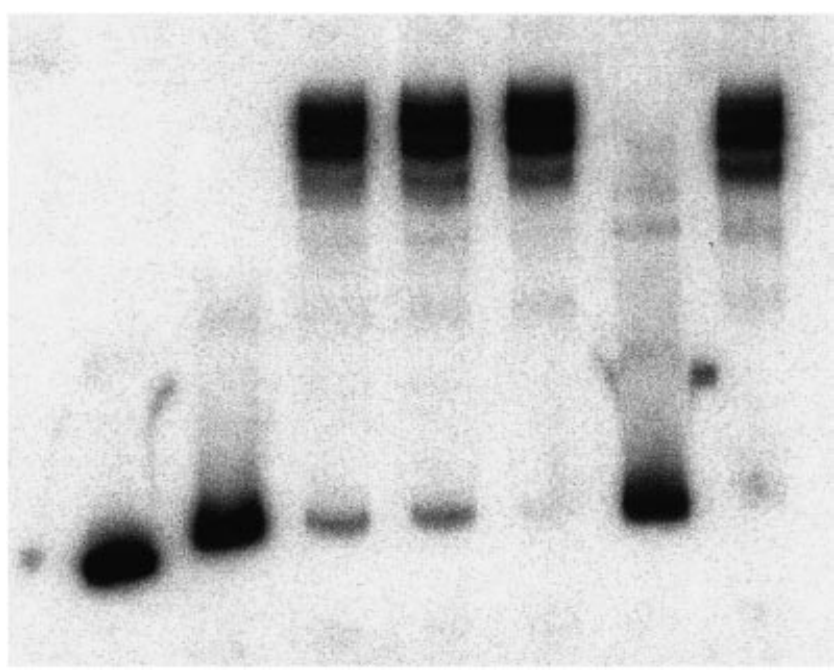

Fig. 3. Detection of HspR binding to the lon promoter. Gel retardation assays were performed with the $300 \mathrm{bp}$ lon promoter fragment as a probe $(0.02 \mathrm{pmol}$ per well). Various quantities of protein extract were added: $0 \mu \mathrm{g}$ (lane1), $1 \mu \mathrm{g}$ (lane 2), 0.25 $\mu \mathrm{g}$ (lane 3), 0.5 $\mu \mathrm{g}$ (lane 4), $1 \mu \mathrm{g}$ (lanes 5, 6 and 7). Crude extracts were prepared from the control strain $E$. coli

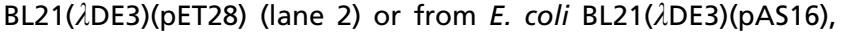
which overproduced HspR (all other lanes). Unlabelled DNA ( $0.1 \mathrm{pmol}$ per well) was added for competition assays: Ion promoter probe (lane 6) or a DNA fragment without HAIR, i.e. the promoter region of the S. lividans heat-inducible gene paralogous to S. coelicolor SCE22.04 (lane 7).

corresponding to the predicted $(29.5 \mathrm{kDa})$ truncated Lon peptide, was present. In the lon mutant, this $30 \mathrm{kDa}$ protein was heat induced, whereas in the lon hspR double mutant it was constitutively synthesized at $30{ }^{\circ} \mathrm{C}$ and $40{ }^{\circ} \mathrm{C}$ (lanes $\mathrm{E}$ and $\mathrm{F}$ ).

\section{Mapping the transcription start site of lon}

The transcription initiation site of the lon gene was determined by primer extension. Primer extension was done on mRNA prepared from cultures grown at $30^{\circ} \mathrm{C}$ or subjected to a $40 \mathrm{~min}$ heat shock at $40{ }^{\circ} \mathrm{C}$. Cultures of wild-type, lon mutant and lon $h s p R$ double mutant were analysed. In the wild-type and in the lon mutant a heatinducible transcript was detected at $40{ }^{\circ} \mathrm{C}$; it started at an adenine in the loop part of the HAIR motif, ATTGAGT(cgatgta)ACTCAAC. In the lon hspR this transcript was detected at $30^{\circ} \mathrm{C}$ and was constitutively expressed independently of the temperature (Fig. 2).

\section{Gel retardation assay with HspR}

Gel mobility-shift assays were performed to determine whether HspR interacts directly with the lon promoter (Fig. 3). The 300 bp lon promoter region was amplified by PCR and labelled using oligonucleotides JU74 and JU75. Cell extracts of the control strain, without HspR, did not affect the mobility of the $300 \mathrm{bp}$ fragment. In presence of $1 \mu \mathrm{g}$ crude extract of the strain expressing $h s p R$, most of the labelled fragment was retarded. Competition experiments were conducted to assess the specificity of the binding. The presence of excess unlabelled probe abolished the observed mobility shift of the labelled lon promoter fragment. These results confirm that HspR binds specifically to the lon promoter region. Bucca et al. (2000) have shown that the DnaK protein must be present for HspR to retard a DNA fragment containing the HAIR motif in gel mobilityshift assays. The multiplicity of the bands of the retarded fragment points to the heterogeneity of the HspR/DnaK complex.

\section{DISCUSSION}

We have identified the first protease in the HAIR/HspR regulon and constructed a viable $S$. lividans lon strain, demonstrating that lon is not essential for the growth and differentiation of Streptomyces.

The co-production of the Lon protease and the DnaK and $\mathrm{ClpB}$ chaperones may present some advantages. Indeed, the Lon protease and the DnaK system have been reported to act in synergy in E. coli, since chaperones detect misfolded proteins that will be either refolded or degraded (Tomoyasu et al., 2001). The cochaperone DnaJ has also been reported to be necessary for the Lon-dependent degradation of some abnormal proteins by keeping the substrates soluble (Jubete et al., 1996).

The HAIR/HspR regulon is not widespread, but it is found in other actinomycetes. HspR controls expression of the $h s p 70$ and $c l p B$ genes in Mycobacterium tuberculosis and Mycobacterium leprae, but these bacteria do not contain any gene orthologous to lon. However, lon orthologues have been found in other mycobacteria, such as Mycobacterium smegmatis (Roudiak et al., 1998), and genome analysis revealed HAIR motifs upstream of lon in M. smegmatis, suggesting that the HAIR/HspR regulation of lon may be widespread among actinomycetes.

Although Streptomyces spp. consistently display two or more paralogues for many genes, the complete genome sequence surprisingly shows that there is only one copy of lon in S. coelicolor. In contrast, in bacteria that generally have a lower number of paralogues, such as B. subtilis and C. crescentus, there are two copies of lon and they have different roles in the cell (Serrano et al., 2001). Likewise, Myxococcus xanthus also has two copies of the lon gene: $\operatorname{lon} V$, which is essential for vegetative growth (Tojo et al., 1993a), and lonD, which is required for development (Tojo et al., 1993b).

A lon mutant has previously been constructed in Mycobacterium smegmatis (Knipfer et al., 1999). This mutant displayed wild-type growth rates, whereas we observed that the growth rate of Streptomyces was reduced by the lon mutation.

S. lividans has been used industrially as a host for expression of several heterologous proteins (Pozidis et 
al., 2001). Utilization of the lon mutant of S. lividans should be considered when low yield of production points to proteolytic degradation of the protein of interest.

\section{ACKNOWLEDGEMENTS}

We thank G. Rapoport and T. Msadek for their advice and constant interest throughout the work, and A. Edelman for correcting this manuscript. This research was supported by the Pasteur Institute, the Centre National de la Recherche Scientifique, the Universite Paris 7 and a grant from the European Commission (Contract no. BIO4-CT98-0051).

\section{REFERENCES}

Blondelet-Rouault, M. H., Weiser, J., Lebrihi, A., Branny, P. \& Pernodet, J. L. (1997). Antibiotic resistance gene cassettes derived from the omega interposon for use in E. coli and Streptomyces. Gene 190, 315-317.

Bucca, G., Hindle, Z. \& Smith, C. P. (1997). Regulation of the $d n a K$ operon of Streptomyces coelicolor A3(2) is governed by HspR, an autoregulatory repressor protein. J Bacteriol 179, 5999-6004.

Bucca, G., Brassington, A. M., Schonfeld, H. J. \& Smith, C. P. (2000). The HspR regulon of Streptomyces coelicolor: a role for the DnaK chaperone as a transcriptional co-repressor. Mol Microbiol 38, 1093-1103.

Bukau, B. (1993). Regulation of the Escherichia coli heat-shock response. Mol Microbiol 9, 671-680.

De Crecy-Lagard, V., Servant-Moisson, P., Viala, J., Grandvalet, C. \& Mazodier, P. (1999). Alteration of the synthesis of the Clp ATPdependent protease affects morphological and physiological differentiation in Streptomyces. Mol Microbiol 32, 505-517.

Gibson, T. J. (1984). Studies on the Epstein-Barr virus genome. $\mathrm{PhD}$ thesis, University of Cambridge.

Goldberg, A. L., Moerschell, R. P., Chung, C. H. \& Maurizi, M. R. (1994). ATP-dependent protease La (Lon) from Escherichia coli. Methods Enzymol 244, 350-375.

Gottesman, S. \& Maurizi, M. R. (1992). Regulation by proteolysis : energy-dependent proteases and their targets. Microbiol Rev 56, 592-621.

Grandvalet, C., Servant, P. \& Mazodier, P. (1997). Disruption of $h s p R$, the repressor gene of the dnaK operon in Streptomyces albus G. Mol Microbiol 23, 77-84.

Grandvalet, C., Rapoport, G. \& Mazodier, P. (1998). $h r c A$ encoding the repressor of the groEL genes in Streptomyces albus G is associated with a second dnaJ gene. J. Bacteriol 180, 5129-5134.

Grandvalet, C., de Crécy-Lagard, V. \& Mazodier, P. (1999). The ClpB ATPase of Streptomyces albus G belongs to the HspR heat shock regulon. Mol Microbiol 31, 521-532.

Herman, C., Thevenet, D., D'Ari, R. \& Bouloc, P. (1995). Degradation of sigma 32, the heat shock regulator in Escherichia coli, is governed by HflB. Proc Natl Acad Sci U S A 92, 3516-3520.

Hopwood, D. A. (1999). Forty years of genetics with Streptomyces: from in vivo through in vitro to in silico. Microbiology 145, 2183-2202.

Hopwood, D. A., Bibb, M. J., Chater, K. F. \& 7 other authors (1985). Genetic Manipulation of Streptomyces. A Laboratory Manual. Norwich: John Innes Foundation.

Jubete, Y., Maurizi, M. R. \& Gottesman, S. (1996). Role of the heat shock protein DnaJ in the lon-dependent degradation of naturally unstable proteins. J Biol Chem 271, 30798-30803.
Knipfer, N., Seth, A., Roudiak, S. G. \& Shrader, T. E. (1999). Species variation in ATP-dependent protein degradation: protease profiles differ between mycobacteria and protease functions differ between Mycobacterium smegmatis and Escherichia coli. Gene 231, 95-104.

Liu, J., Cosby, W. M. \& Zuber, P. (1999). Role of lon and ClpX in the post-translational regulation of a sigma subunit of RNA polymerase required for cellular differentiation in Bacillus subtilis. Mol Microbiol 33, 415-428.

Murakami, T., Holt, T. G. \& Thompson, C. J. (1989). Thiostreptoninduced gene expression in Streptomyces lividans. J Bacteriol 171, 1459-1466.

Muth, G., Nubbaumer, B., Wohlleben, W. \& Pühler, A. (1989). A vector system with temperature-sensitive replication for gene disruption and mutational cloning in streptomycetes. Mol Gen Genet 219, 341-348.

Pozidis, C., Lammertyn, E., Politou, A. S., Anné, J., Tsiftsoglou, A. S., Sianidis, G. \& Economou, A. (2001). Protein secretion biotechnology using Streptomyces lividans: large-scale production of functional trimeric tumor necrosis factor alpha. Biotechnol Bioeng 72, 611-619.

Roudiak, S. G., Seth, A., Knipfer, N. \& Shrader, T. E. (1998). The lon protease from Mycobacterium smegmatis: molecular cloning, sequence analysis, functional expression, and enzymatic characterization. Biochemistry 37, 377-386.

Sambrook, J., Frisch, E. F. \& Maniatis, T. (1989). Molecular Cloning: a Laboratory Manual. Cold Spring Harbor, NY: Cold Spring Harbor Laboratory.

Schweder, T., Lee, K.-H., Lomovskaya, O. \& Matin, A. (1996). Regulation of Escherichia coli starvation sigma factor $\left(\sigma^{\mathrm{s}}\right)$ by ClpXP protease. J. Bacteriol 178, 470-476.

Serrano, M., Hovel, S., Moran, C. P., Jr, Henriques, A. O. \& Volker, U. (2001). Forespore-specific transcription of the lonB gene during sporulation in Bacillus subtilis. J. Bacteriol 183, 2995-3003.

Servant, P. \& Mazodier, P. (1996). Heat induction of $h s p 18$ gene expression in Streptomyces albus G: transcriptional and posttranscriptional regulation. J. Bacteriol 178, 7031-7036.

Spohn, G. \& Scarlato, V. (1999). The autoregulatory HspR repressor protein governs chaperone gene transcription in Helicobacter pylori. Mol Microbiol 34, 663-674.

Sun, J., Kelemen, G. H., Fernandez-Abalos, J. M. \& Bibb, M. J. (1999). Green fluorescent protein as a reporter for spatial and temporal gene expression in Streptomyces coelicolor A3(2). Microbiology 145, 2221-2227.

Tojo, N., Inouye, S. \& Komano, T. (1993a). Cloning and nucleotide sequence of the Myxococcus xanthus lon gene: indispensability of lon for vegetative growth. J Bacteriol 175, 2271-2277.

Tojo, N., Inouye, S. \& Komano, T. (1993b). The lonD gene is homologous to the lon gene encoding an ATP-dependent protease and is essential for the development of Myxococcus xanthus. J Bacteriol 175, 4545-4549.

Tomoyasu, T., Mogk, A., Langen, H., Goloubinoff, P. \& Bukau, B. (2001). Genetic dissection of the roles of chaperones and proteases in protein folding and degradation in the Escherichia coli cytosol. Mol Microbiol 40, 397-413.

Turgay, K., Hahn, J., Burghoorn, J. \& Dubnau, D. (1998). Competence in Bacillus subtilis is controlled by regulated proteolysis of a transcription factor. EMBO J 17, 6730-6738.

Viala, J., Rapoport, G. \& Mazodier, P. (2000). The $c l p P$ multigenic family in Streptomyces lividans: conditional expression of the clpP3 clpP4 operon is controlled by PopR, a novel transcriptional activator. Mol Microbiol 38, 602-612. 
lon belongs to the HAIR/HspR regulon in S. lividans

Wright, R., Stephens, C., Zweiger, G., Shapiro, L. \& Alley, M. R. (1996). Caulobacter Lon protease has a critical role in cell-cycle control of DNA methylation. Genes Dev 10, 1532-1542.

Yanisch-Perron, C., Vieira, J. \& Messing, J. (1985). Improved M13 phage cloning vectors and host strains: nucleotide sequences of the M13mp18 and pUC19 vectors. Gene 33, 103-119.
Yura, T., Nagai, H. \& Mori, H. (1993). Regulation of the heat-shock response in bacteria. Annu Rev Microbiol 47, 321-350.

Received 1 November 2001; revised 30 January 2002; accepted 13 February 2002. 